Aim of the study: Due to the emergence of new therapeutic opportunities in the second-line treatment of metastatic renal cell carcinoma, the choice of the appropriate medication requires consideration. Making the selection one should take into account the likelihood of response, the probability of toxicity, properties of the drug and the clinical characteristics of the patient. Aim of the work was to confirm antitumor efficacy of axitinib in patients with metastatic clear-cell renal-cell carcinoma in the second line treatment remaining under the care of our institution. The primary objective was to determine antitumor activity, secondary - to evaluate progression free survival, safety of the treatment and to analyse clinical characteristics of treated population.

Results: Treatment records of $27 \mathrm{pa}$ tients (9 females, 18 males) treated from October 2014 to the present (July 2016) were reviewed. The median duration of treatment which corresponds to the time to disease progression in observed population was 6 months (range: under 1 month - 16 months). 1 patient (3.7\%) had got objective response (PR, partial remission). Clinical benefit rate (PR + SD (stable disease) was $66 \%$. 9 patients (33.33\%) experienced treatment toxicity only in the first degree of CTCAE (common toxicity criteria for adverse events), 11 patients (40.74\%) presented the second degree toxicity and $5 \mathrm{pa}$ tients $(18.5 \%)$ - third degree. The most commonly reported treatment related adverse events were diarrhea ( $47 \%)$, fatigue $(26 \%)$, hand-foot syndrome $(26 \%)$, deterioration of blood pressure control $(22.2 \%)$, abnormal liver function tests (18.5\%), mucositis (11.1\%).We observed 3 cases of unacceptable toxicity.

Conclusions: Axitinib confirms its effectiveness also in situation outside clinical trials, however, it is characterized by significant toxicity. Therefore, qualification for treatment should take into account the clinical patient characteristics. Effective diagnosis and treatment of side effects and dose optimization are the key skills of the attending physician.

Key words: axitinib, metastatic renal cell carcinoma, efficacy, toxicity.

Contemp Oncol (Pozn) 2016; 20 (6): 481-485 DOI: https://doi.org/10.5114/wo.2016.65609

\section{Axitinib in metastatic renal cell carcinoma: single center experience}

\author{
Agnieszka Buraczewska, Joanna Kardas
}

Department of Oncology, Military Institute of Medicine, Warsaw, Poland

\section{Introduction}

Kidney cancer accounts for approximately 2-3\% of malignant tumors in adults. The peak incidence falls on the $7^{\text {th }}$ decade of life. Currently, more than $70 \%$ of kidney cancer is diagnosed in the organ-limited form. This percentage increased significantly in recent years mainly due to the wide introduction of imaging techniques. In 2011 in Poland kidney cancer was diagnosed in more than 2,700 men and 1,800 women and died from the disease 1500 men and 1000 women [1]. Men dominate among patients (1,5:1) [2].

Kidney cancer usually occurs sporadically and family circumstances account for only $2 \%$ of cases. The etiology of sporadic cases is not known, however cigarette smoking, obesity and dialysis are associated with higher incidence of the disease [1].

The most common histological type of kidney cancer is renal cell carcinoma, which accounts for about $85-90 \%$. Within this type, one can distinguish the most common - clear-cell renal-cell carcinoma - $80 \%$ with worst prognosis, followed by papillary subtype $-10-15 \%$ and chromophobe $-4-5 \%$ [3].

Surgical treatment is the main element of proceedings in both organ confined and metastatic disease (resection of metastases). Causal drug therapy is a form of palliative treatment of metastatic disease. In Poland currently are reimbursed two molecularly targeted drugs in first-line treatment (sunitinib, pazopanib), two in second-line (everolimus, axitinib), interferon $\alpha$ therapy as first line treatment for selected patients (favorable prognostic group, metastatic lesions limited to the lungs) and sorafenib only after interferon.

The latest drug available for Polish patients by mid-2014 under the National Health Fund reimbursement program is axitinib. It is a potent and selective inhibitor of tyrosine kinase vascular endothelial growth factor receptor (VEGFR)-1, VEGFR-2 and VEGFR-3, involved in the pathological angiogenesis. Axitinib strongly inhibits VEGF-dependent proliferation and survival of endothelial cells. It is indicated for the treatment of adults with advanced renal cell carcinoma after failure of prior sunitinib or cytokine treatment [4].

\section{Aim of the study}

This analysis was carried out to confirm antitumor efficacy of axitinib in patients with metastatic clear-cell renal-cell carcinoma in the second line treatment remaining under the care of our institution. The primary objective was to determine antitumor activity (response rate) of axitinib, secondary objectives include evaluation of duration of response, progression free survival and safety as well as analysis of clinical characteristics of treated population.

\section{Material and methods}

This is a retrospective analysis of patients treated in Oncology Clinic of Military Medical Institute with axitinib. Source of data was treatment records of patients.

An eligibility criteria were following: 1) histologically confirmed diagnosis of clear cell or mixed renal carcinoma with predominantly (over 50\%) 
clear-cell component; 2) disseminated disease; 3) failure of prior treatment with multikinase inhibitors (sunitinib, pazopanib) in the first-line treatment or after failure of cytokines; 4) prior radical nephrectomy or nephrone sparing procedure; 5) absence of metastases in the central nervous system or stable state after their removal or radiation therapy; 6) Karnofsky 80-100 performance status; 7) favourable or intermediate prognosis according to MSKCC (Memorial Sloan-Kettering Cancer Center); 8) the absence of uncontrolled cardiovascular diseases, adequate organ efficiency, thyroid function within normal limits.

Treatment was ended due to progression during treatment, persistent deterioration of performance status or quality of life, unacceptable or recurrent over grade 3 CTCAE (Common Terminology Criteria for Adverse Events) toxicity, patient will or death.

Baseline assessment included medical history, physical examination taking into account performance status according to ECOG (Eastern Cooperative Oncology Group) scale, tumor imaging with computed tomography (CT), laboratory tests (hematology, biochemistry). Assessments through the treatment take into account physical examination, performance status, adverse events recording and monitoring, CT imaging every approximately 3 months of treatment, hematology and biochemistry profiles every month.

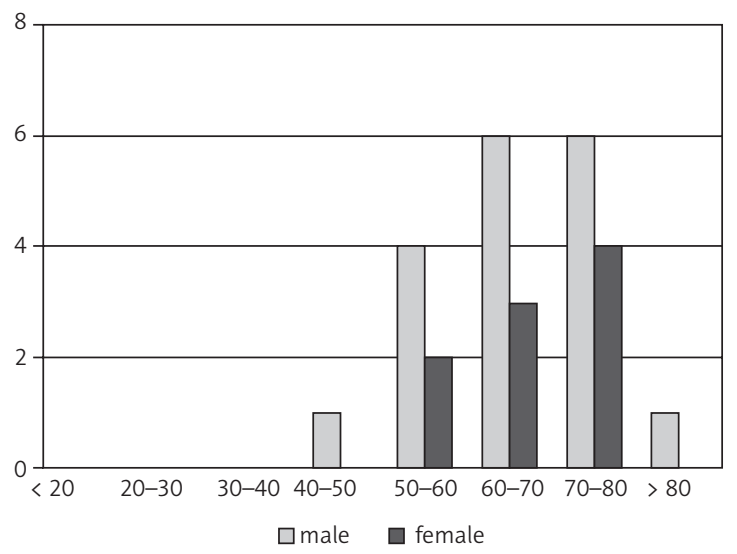

Fig. 1. Age and sex distribution

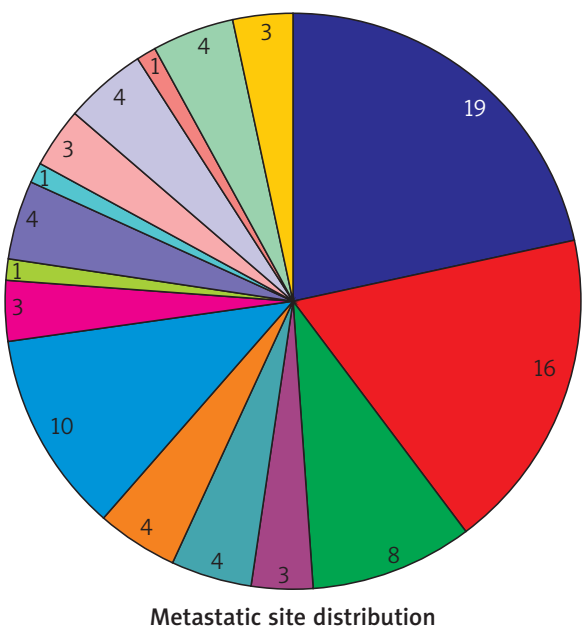

lungs

$\square$ bones

liver

$\square$ brain

the remaining

$\square$ kidney

$\square$ adrenals

$\square$ mediastinum

$\square$ pancreas

$\square$ salivary glands

$\square$ soft tissues

$\square$ skin

$\square$ muscles

$\square$ local recurrence

$\square$ testis

$\square$ plural effusion

$\square$ retroperitoneal

space

Metastatic site distribution

Fig. 2. Metastatic site distribution
Treatment effect was evaluated according to the RECIST 1.1 (Response Evaluation Criteria in Solid Tumors). In turn toxicity was graded after CTCAE.

\section{Results}

A total of 27 patients ( 9 females, 18 males) treated from October 2014 to the present (July 2016), were reviewed. The median age was 63 years (range: 40-83). Men were twice more numerous than women. All patients were current or ex-smokers. The majority of them (23 persons, i.e. $85 \%$ ) suffered from other serious illnesses (up to 7) including hypertension (19 persons - 70\%), coronary artery disease (9 persons - 33\%), hyperlipidemia ( 6 persons $-22 \%$ ) and diabetes ( 6 persons $-22 \%$ ). Other diseases occurring in the observed group were: abdominal aortic aneurysm (1 person), history of ischemic stroke (2 persons), chronic kidney disease (3 persons), benign prostatic hyperplasia (4 persons), gout (2 persons), ulcerative colitis (1 person), chronic obstructive pulmonary disease (confirmed only in 2 persons, surprisingly), asthma (1 person).

The median duration of treatment which corresponds to the time to disease progression in observed population was 6 months (range: under 1 month - 16 months). 12 patients $(44.4 \%=$ over one third) completed treatment due to disease progression found in the imaging studies, assessed according to the RECIST 1.1. Other reasons for stopping treatment were: sustained performance status of 70 or lower on the Karnofsky scale (1 patient), significant deterioration in the quality of life during treatment (5 patients). In patients treated at our center we also noted 4 deaths of other (1) or unknown (3) causes. Eight patients are currently still treated with axitinib. We did not observe symptoms of hypersensitivity to axitinib or any of the excipients.

In the study population 1 patient (3.7\%) had got objective response (partial remission - PR). Clinical benefit rate (PR+SD (stable disease) was 66\%. Median PFS in this study was 6 months (24 weeks) with a range of under 1 to 15 months. Only in 3 cases (11.11\%) it was possible to escalate the dose over the standard one $(2 \times 5 \mathrm{mg}$ per day) due to very good tolerance. One of these patients was treated with the dose $2 \times 10 \mathrm{mg}$ per day with minimal toxicity. Eight patients (29.62\%) was unable to stand the dose of $2 \times 5 \mathrm{mg}$ per day, they had their dose reduced, in three cases even to $2 \times 2 \mathrm{mg}$. Sixteen patients (59\%) remained on the initial dose of $2 \times 5 \mathrm{mg}$ daily.

Nine patients i.e. $33.33 \%$ experienced treatment toxicity only in the first degree of CTCAE (common toxicity criteria for adverse events) namely elevated transaminases, asthenia, mucositis, diarrhea, hand-foot syndrome. Eleven patients $(40.74 \%)$ presented the second degree toxicity according to CTCAE and 5 patients (18.5\%) - third degree.

The most commonly reported treatment related adverse events were diarrhea (11 persons - 47\%), fatigue (7 persons - 26\%), hand-foot syndrome (7 persons $26 \%$ ), deterioration of blood pressure control (6 persons $-22.2 \%)$, abnormal liver function tests (5 persons $-18.5 \%$ ), mucositis (3 persons - 11.1\%).

We observed 3 cases of unacceptable toxicity. The first one it was asymptomatic colonic perforation, disclosed in 
Table 1. Patient baseline characteristics

$\begin{array}{lc}\text { Total intent to treat population } & 27(100 \%) \\ \begin{array}{l}\text { Gender: } \\ \text { men }\end{array} & 18(66.6 \%) \\ \text { women } & 9(33.3 \%) \\ \text { Age, median (range), year } & 63(40-83) \\ \text { ECOG performance status: } & \\ 0 & 6(22.2 \%) \\ 1 & 12(44.4 \%) \\ 2 & 9(33.3 \%) \\ \text { Prior systemic treatment: } & \\ \text { interferon } \alpha & 0 \\ \text { sunitinib } & 21(77.7 \%) \\ \text { pazopanib } & 6(22.2 \%) \\ \text { Main sites of metastases: } & \\ \text { lungs } & 19(70.3 \%) \\ \text { bones } & 16(59.2 \%) \\ \text { liver } & 8(29.6 \%) \\ \text { brain } & 3(11.1 \%) \\ \text { the remaining kidney } & 4(14.8 \%) \\ \text { Number of metastatic sites: } & \\ 2 & 19(70.3 \%) \\ >2 & \end{array}$

$\mathrm{CT}$ in a patient who underwent the metastasis resection from the colon a few months before. The second one it was myocardial infarction and the third one - stroke with mild neurologic deficit.

\section{Discussion}

Metastatic renal cell carcinoma is one of the most challenging malignancies to treat. It is resistant to cytotoxic chemotherapy and shows only limited sensitivity to radiotherapy. In the era of cytokine therapy such as interferon $\alpha$ or interleukin 2 approximately $15 \%$ of patients responded to that treatment [5]. This scenario changed significantly with the invention of targeted therapy. The vascular endothelial growth factor binding monoclonal antibody - bevacizumab in combination with interferon $\alpha$ were approved in Europe in 2007, the mammalian target of rapamycin inhibitor everolimus in 2009. Sunitinib was approved in 2007, then joined him sorafenib and pazopanib (2010). Axitinib which inhibits the vascular endothelial growth factor receptor (VEGFR) at subnanomolar level is considered a next-generation agent [6]. All those medications have wide range of substantial side effects, some of them significantly impairing quality of life and some life-threatening. Management of these side effects represent a challenge for the physician. On one hand, dosage reduction and treatment interruption should be avoided to minimize the risk for progression, on the other hand, only mild toxicity is tolerable for the patient. Knowledge of the drug characteristics, its side effects, opportunities to optimize treatment by seeking to escalate the dose where possible seems to be crucial to conduct safe and effective treatment with axitinib [7-11].

In the pivotal trial-AXIS, treatment with axitinib resulted in significantly longer PFS (progression free survival) compared with sorafenib. The median PFS was 6.7 months with axitinib compared to 4.7 months with sorafenib (hazard ratio $0.665 ; 95 \% \mathrm{Cl}: 0.544-0.812$; one-sided $p<0.0001$ ).
Table 2. Distribution of comorbidities in the group

\begin{tabular}{|lc|}
\hline Comorbidity & Number of patients \\
\hline Hypertension & $19(70 \%)$ \\
\hline Coronary disease & $9(33 \%)$ \\
\hline Hyperlipidaemia & $6(22 \%)$ \\
\hline Diabetes & $6(22 \%)$ \\
\hline Benign prostate hyperplasia & $4(14.8 \%)$ \\
\hline Chronic kidney disease & $3(11 \%)$ \\
\hline Gout & $2(7.4 \%)$ \\
\hline Chronic obstructive pulmonary disease & $2(7.4 \%)$ \\
\hline Ischaemic stroke & $2(7.4 \%)$ \\
\hline Ulcerative colitis & $1(3.7 \%)$ \\
\hline Abdominal aortic aneurysm & $1(3.7 \%)$ \\
\hline Varicose legs & $1(3.7 \%)$ \\
\hline Gastroesophageal reflux & $1(3.7 \%)$ \\
\hline Asthma & $1(3.7 \%)$ \\
\hline
\end{tabular}

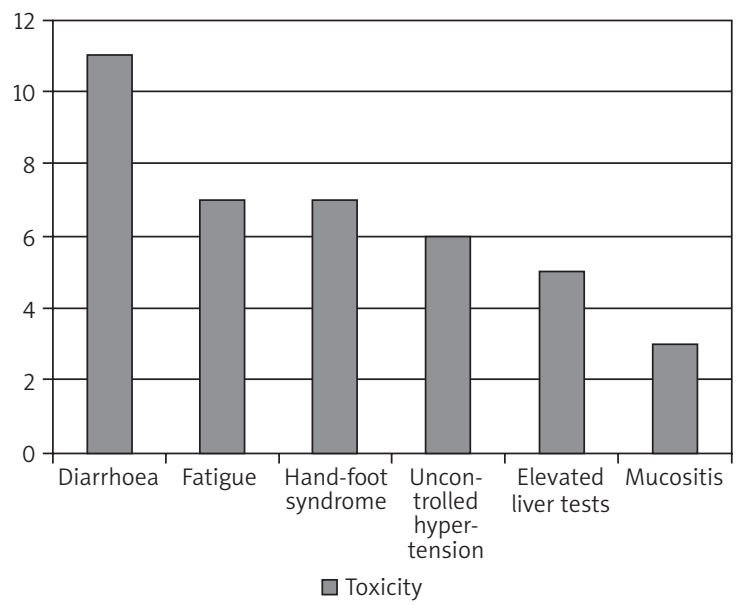

Fig. 3. Toxicity

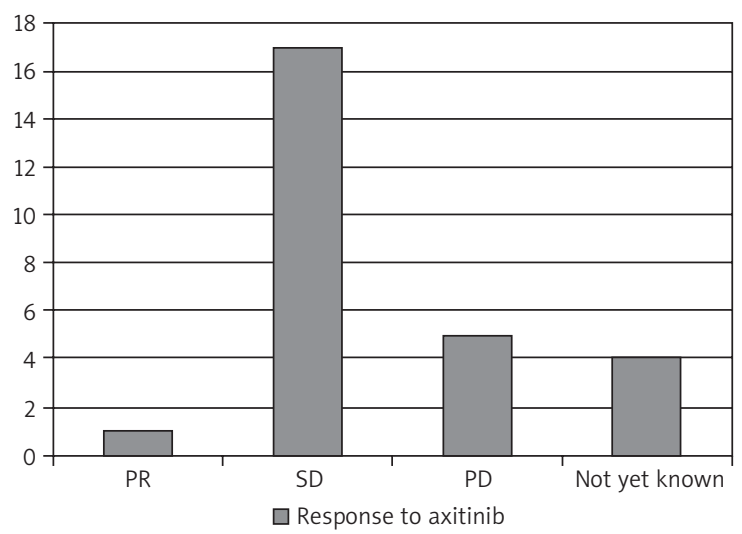

Fig. 4. Response to axitinib

Treatment was discontinued because of toxic effects in 14 (4\%) of 359 patients treated with axitinib and 29 (8\%) of 355 patients treated with sorafenib. The most common adverse events were diarrhea, hypertension and fatigue in the axitinib arm and diarrhea, palmar-plantar erythrodysaesthesia and alopecia in the sorafenib arm [12]. 


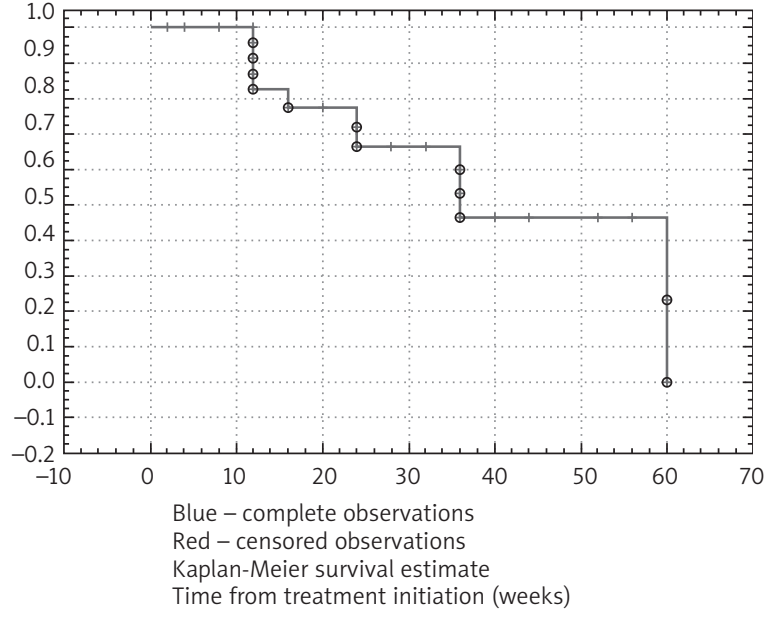

Fig. 5. Kaplan-Meier curve for progression free survival

\begin{tabular}{|c|c|c|c|}
\hline \multicolumn{4}{|c|}{ Kaplan-Meier analysis (PFS) } \\
\hline \multicolumn{4}{|c|}{ + censored observations } \\
\hline $\begin{array}{l}\text { Number } \\
\text { of cases }\end{array}$ & Time & $\begin{array}{c}\text { Cumulative } \\
\text { survival }\end{array}$ & $\begin{array}{c}\text { Standard } \\
\text { error }\end{array}$ \\
\hline
\end{tabular}

\begin{tabular}{|c|c|c|c|}
\hline $19+$ & 2.00000 & & \\
\hline $27+$ & 4.00000 & & \\
\hline $17+$ & 8.00000 & & \\
\hline $13+$ & 8.00000 & & \\
\hline 5 & 12.00000 & 0.956522 & 0.042523 \\
\hline 9 & 12.00000 & 0.913044 & 0.058753 \\
\hline 10 & 12.00000 & 0.869565 & 0.070224 \\
\hline 2 & 12.00000 & 0.826087 & 0.079034 \\
\hline $20+$ & 12.00000 & & \\
\hline $6+$ & 12.00000 & & \\
\hline $15+$ & 12.00000 & & \\
\hline 4 & 16.00000 & 0.774457 & 0.089382 \\
\hline $3+$ & 20.00000 & & \\
\hline 14 & 24.00000 & 0.719138 & 0.098641 \\
\hline 16 & 24.00000 & 0.663820 & 0.105430 \\
\hline $21+$ & 28.00000 & & \\
\hline $1+$ & 32.00000 & & \\
\hline 11 & 36.00000 & 0.597438 & 0.113883 \\
\hline 24 & 36.00000 & 0.531056 & 0.119014 \\
\hline 22 & 36.00000 & 0.464674 & 0.121245 \\
\hline $12+$ & 40.00000 & & \\
\hline $8+$ & 44.00000 & & \\
\hline $26+$ & 52.00000 & & \\
\hline $7+$ & 52.00000 & & \\
\hline $18+$ & 56.00000 & & \\
\hline 25 & 60.00000 & 0.232337 & 0.175115 \\
\hline 23 & 60.00000 & 0.000000 & 0.000000 \\
\hline
\end{tabular}

Fig. 6. Kaplan-Meier analysis
From Japan comes a report about the effectiveness of the drug in the first-line setting with median duration of the administration 10.8 months, $27.8 \%$ partial response and $50 \%$ disease stabilization [13].

The recommended clinical starting dose of axitinib is $5 \mathrm{mg}$ twice daily, taken with or without food. Dose increase up to a maximum of $10 \mathrm{mg}$ twice daily or reduction is permitted and even suggested based on individual tolerability. Axitinib pharmacokinetics are dose-proportional within 1-20 mg twice daily, which includes the clinical dose range. It has a short effective plasma half-life (range 2.5-6.1 h) and reaches maximum plasma concentration within $4 \mathrm{~h}$ of oral administration. It is eliminated via hepatobiliary excretion with negligible urinary excretion $[14,15]$.

Patients who developed diastolic blood pressure $>90$ $\mathrm{mmHg}$ were noted to have significantly longer median overall survival and overall response rates when compared to normotensive patients $[16,17]$. Therefore, the manufacturer recommends escalating the twice daily dose to $7 \mathrm{mg}$ and $10 \mathrm{mg}$, as tolerated, if there is no significant increase in blood pressure on treatment [16]. Axitinib is the only targeted agent that benefits from individual titration in terms of efficacy [18]. As optimal axitinib exposure differs among patients, blood pressure monitoring and pharmacokinetics are among the factors that help to individualize axitinib dosage $[19,20]$.

Although generally we expect that data from clinical practice differ from those of the clinical trials, here treatment efficacy measured by PFS almost coincides with the values from AXIS. The incidence of toxicity, especially unacceptable or in the third degree (often related to laboratory abnormalities only), seems to be quite high as for palliative treatment, that is why the ability to manage side effects promptly is so important. It appears that many comorbidities, particularly of cardiovascular nature, contribute to increased treatment toxicity (especially life-threatening complications) and indirectly to reduced efficacy.

In majority of patients who remained on the initial dose of $2 \times 5 \mathrm{mg}$, it was unclear why the clinician did not try to individualize the dose. This may raise the suspicion that he was not aware of how meaningful the attempts of dose escalation are. One can suspect that increasing the dose in patients not showing severe toxicity would lead to better treatment effect.

\section{Conclusions}

The results of the study confirm that axitinib have substantial antitumor effect against metastatic clear cell renal cell carcinoma. Management of side effects, adequate counseling, tailoring the dose and careful follow-up are crucial in maximizing the duration of disease control in second line setting.

Real-life data in terms of efficacy do not differ much from those from clinical trials, although only at the expense of increased toxicity. That is why meticulous monitoring of patients and proper side effects treatment should be required by trained and dedicated personnel.

The authors declare no conflict of interest. 


\section{References}

1. Onkologia kliniczna. Krzakowski M, Potemski P, Warzocha K, Wysocki P (eds.). Vol. II. Via Medica, Gdańsk 2015.

2. Zalecenia postepowania diagnostyczno-terapeutycznego w nowotworach złośliwych 2013 rok. Krzakowski M, Warzocha K (eds.). Vol. 1. Via Medica, Gdańsk 2013.

3. Jassem J, Krzakowski M, Senkus-Konefka E, Zdrojowy R. Nowotwory układu moczowo-płciowego. Via Medica, Gdańsk 2013.

4. Charakterystyka Produktu Leczniczego INLYTA: www.ema.europa. eu/docs/pl_PL/document_library/.../WC500132188.pdf

5. Escudier B, Chevreau C, Lasset C, et al. Cytokines in metastatic renal cell carcinoma: Is it useful to switch to interleukin 2 or inter feron after failure of a first treatment? Groupe Francais d'Immunotherapie. J Clin Oncol 1999; 17: 2039-43.

6. Grunwald V, Merseburger AS. Axitinib for the treatment of patients with advanced metastatic renal cell carcinoma after failure of prior systemic treatment. Onco Targets Ther 2012; 5: 111-7.

7. Lieb V, Rink M, Sikic D, Keck B. Side effect management of tyrosine kinase inhibitors in urology: Gastrointestinal side effects. Urologe A 2016; 55: 805-12.

8. Porta C, Tortora G, Linassier C, et al. Maximising the duration of disease control in metastatic renal cell carcinoma with targeted agents: an expert agreement. Med Oncol 2012; 29: 1896-907.

9. Larkin J, Fishman M, Wood L, et al. Axitinib for the treatment of metastatic renal cell carcinoma: recommendations for therapy management to optimize outcomes. Am J Clin Oncol 2014; 37: 397-403.

10. Larkin J, Paine A, Tumur I, et al. Second-line treatments for the management of advanced renal cell carcinoma: systematic review and metaanalysis. Expert Opin Pharmacother 2013; 14: 27-39.

11. Calvo E, Ravaud A, Bellmunt J. What is the optimal therapy for patients with metastatic renal cell carcinoma who progress on an initial VEGFR-TKI? Cancer Treat Rev 2013; 39: 366-74.

12. Rini B, Escudier B, Tomczak P, et al. Comparative effectiveness of axitinib versus sorafenib in advanced renal cell carcinoma (AXIS): a randomised phase 3 trial. Lancet 2011; 378: 1931-9.

13. Koie T, Ohyama C, Yoneyama T, et al. Feasibility of axitinib as first-line therapy for advanced or metastatic renal cell carcinoma: a single-institution experience in Japan. BMC Urol 2015; 16; 15: 32.

14. Chen Y, Tortorici MA, Garrett M, Hee B, Klamerus KJ, Pithavala YK. Clinical pharmacology of axitinib. Clin Pharmacokinet 2013; 52: 713-25.

15. Akaza H, Fukuyama T. Axitinib for the treatment of advanced renal cell carcinoma. Expert Opin Pharmacother 2014; 15: 283-97.

16. Gunnarsson O, Pfanzelter NR, Cohen RB, Keefe SM. Evaluating the safety and efficacy of axitinib in the treatment of advanced renal cell carcinoma. Cancer Manag Res 2015; 7: 65-73.

17. Rini B, Garrett M, Poland B, et al. Axitinib in metastatic renal cell carcinoma; results of a pharmacokinetic and pharmacodynamics analysis. J Clin Pharmacol 2013; 53: 491-504.

18. Gross-Gupil M, Francois L, Quivy A, Ravaud A. Axitinib: a review of its safety and efficacy in the treatment of adults with advanced renal cell carcinoma. Clin Med Insights Oncol 2013; 7: 269-77.

19. Rini B, Melichar B, Fishman MN, Oya M, Pithavala YK, Chen Y, Bair AH, Grünwald V. Axitinib dose titration: analyses of exposure, blood pressure and clinical response from a randomized phase II study in metastatic renal cell carcinoma. Ann Oncol 2015; 26: 1372-7.

20. Rini B, Quinn D, Baum M, et al. Hypertension among patients with renal cell carcinoma receiving axitinib or sorafenib: analysis from the randomized phase III AXIS trial. Target Oncol 2015; 10: 45-53.

\section{Address for correspondence}

\section{Agnieszka Buraczewska}

Department of Oncology

Military Institute of Medicine

Szaserów 128

04-141 Warsaw, Poland

e-mail:agnb102@gmail.com

Submitted: 16.07 .2016

Accepted: $\quad 30.09 .2016$ 